\title{
A QUÍMICA DO ESTANHO NO SÉCULO 18, OU COMO UMA CONSULTA SE TRANSFORMOU NUM PROJETO DE PESQUISA
}

\section{Carlos A. L. Filgueiras}

Departamento de Química Inorgânica, Instituto de Química, Universidade Federal do Rio de Janeiro, CP 68563, 21945-970 Rio de Janeiro - RJ

Recebido em 14/1/02; aceito em 24/7/02

\begin{abstract}
TIN CHEMISTRY IN THE $18^{\text {th }}$ CENTURY, OR HOW AN INQUIRY BECAME A RESEARCH PROJECT. An ominous suspicion arose in France in the second half of the $18^{\text {th }}$ century, that household tin objects might be contaminated with arsenic. Charged with the task of studying and deciding the question, the chemists Pierre Bayen and Louis Charlard set up a comprehensive research project, which resulted in a book describing the whole enterprise. It is very gratifying to analyse this work today, for the many lights it sheds on the way chemistry was practised and reasoned at the time, and for the whiff of modernity we are presented with.
\end{abstract}

Keywords: tin chemistry; metal toxicity; eighteenth century chemistry.

\section{INTRODUÇÃO: A QUÍMICA DO ESTANHO ATÉ O SÉCULO 18}

A preocupação com o efeito tóxico de certos metais no organismo, que muitos supõem ser uma cogitação contemporânea, na realidade vem de longa data. No reinado de Luís XV, Cadet de Vaux, Censor Real, membro do Colégio de Farmácia e Inspetor dos Objetos de Salubridade havia tomado várias providências relativas à proteção da população francesa contra este tipo de contaminação. Para este efeito solicitara do governo a supressão dos vasilhames de cobre para o leite e das mantas de chumbo com que eram revestidos os balcões dos comerciantes de vinho. Ademais, propusera substituir o chumbo pelo estanho. Em face dessa situação, o Inspetor Geral de Polícia julgou importante subsidiar a opinião do governo com dados técnicos. Com essa finalidade, ele "encarregou o Colégio de Farmácia de se ocupar desse assunto e determinar o grau de confiança que o estanho merecia nos usos domésticos". Em 1778 o Colégio de Farmácia encarregou três de seus membros, químicos e farmacêuticos, de realizar um estudo e decidir se o uso de utensílios domésticos de estanho era ou não nocivo à saúde. Os três pesquisadores designados foram Pierre Bayen, Louis Martin Charlard e Hilaire Martin Rouelle, irmão mais novo do conhecido químico Guillaume François Rouelle, que havia sido professor de Lavoisier. Todavia, ao começarem os trabalhos, em 1779, Hilaire Rouelle viria a falecer, de sorte que o trabalho ficou a cargo dos dois primeiros. Destes, Bayen (1725-1798), Mestre-Boticário do exército francês, é de longe o mais conhecido. Bayen distinguiu-se numa série de trabalhos químicos importantes, o mais notório deles tendo sido sua investigação a respeito das propriedades da cal (óxido) de mercúrio. Ele publicou várias memórias sobre este assunto entre 1774 e 1775, coincidentes, portanto, com o trabalho que também vinha sendo realizado no mesmo período por Lavoisier. Bayen mostrou que a cal de mercúrio se reduzia a mercúrio metálico quando aquecida, com ou sem a presença de carvão, e em ambos os casos liberando um gás, que ele não testou e supôs fosse nos dois casos o ar fixo (gás carbônico) ${ }^{2}$. O assunto só viria a ser esclarecido definitivamente por Lavoisier.

*e-mail: calf@iq.ufrj.br
Bayen e Charlard acabaram por transformar a consulta governamental num verdadeiro projeto de pesquisa, engenhoso e crítico, apesar do estado ainda relativamente tosco da química da época para trabalhos analíticos dessa envergadura. A química que se praticava ainda era muito qualitativa, ao passo que eles tentavam sempre quantificar seus experimentos, buscando uma conexão entre os argumentos qualitativos e quantitativos. Dessa forma, estavam muito próximos à química lavoisiana, que lhes era familiar através da Academia das Ciências, e já distantes da química do flogisto, que nunca é invocada por eles, mas ainda tinha prestígio em muitos centros europeus. Os dois conseguiram levar a bom termo a empreitada e seu trabalho resultou num livro notável de quase 300 páginas, saído à luz em 1781, oito anos antes do Tratado Elementar de Química de Lavoisier. A análise deste livro após mais de dois séculos ilustra vários aspectos: primeiro, os autores apresentam de forma exemplar o estado da química um pouco antes do triunfo da química lavoisiana, ainda em gestação, e a química que se nos depara busca exprimir-se, como dito atrás, tanto qualitativa como quantitativamente; segundo, é possível acompanhar, passo a passo, as decisões, os experimentos, os raciocínios e as conclusões, ao longo de todo o desenrolar do projeto; terceiro, apesar do fosso entre as teorias, conhecimentos, instrumental e meios disponíveis entre a ciência de hoje e a do século 18 , pode-se comparar a forma de proceder nas duas épocas. Isso fica claro ao considerar como são tomadas novas decisões à medida que surgem os resultados. Bayen e Charlard aplicavam a nova forma de fazer química de forma rigorosa e precisa, como se verá no decorrer deste artigo, e nisso há que reconhecer sua modernidade.

Na Europa da Idade Moderna o uso do estanho se espalhara em inúmeras aplicações domésticas, como em baixelas e vasilhas de toda natureza. $\mathrm{O}$ conhecimento da química deste metal também progrediu consideravelmente. Uma das obras de química mais influentes do final do século 17 a meados do século 18 foi o Cours de Chymie do químico francês Nicolas Lemery (1645-1715), publicada originalmente em 1675, mas que teve dezenas de edições até 1757 , tanto em francês como em outras línguas. A edição de 1757, publicada postumamente, teve inúmeros acréscimos de autoria do químico Théodore Baron d'Hénouville (1715-1768). O livro abrange toda a química, e nele se encontra um capítulo inteiro dedicado ao estanho, refletindo o conhecimento existente uma geração antes do trabalho 
de Bayen e Charlard. O texto abre com a descrição do metal ${ }^{3}$ :

"O estanho, chamado pelos antigos de chumbo branco, é um metal que se aproxima da prata em cor, mas que dela muito difere em figuras de poros, em solidez e em peso: (a) deu-se-lhe o nome do Planeta de Júpiter, do qual se pretendeu que ele recebesse as influências; é uma matéria maleável, sulfurosa $a^{4},(b)$ e muito fácil de fundir: encontra-se em muitas minas, principalmente na Inglaterra, a qual é chamada, por esta razão, de Ilha do Estanho...

O estanho mais puro é aquele que vem em salmões, da Cornualha, província da Inglaterra; ele é chamado de Estanho aplainado; devese preferi-lo aos outros para as operações da química.

O estanho comum que se vende nos picheleiros contém um pouco de chumbo e de cobre amarelo com os quais ele foi ligado."

$\mathrm{O}$ livro de Lemery, mesmo na edição citada, contemporânea dos dois químicos aqui tratados, ainda tem um sabor arcaizante que não mais estará presente na obra de Bayen e Charlard.

Já em 1740 haviam sido publicadas, no volume da Academia Real das Ciências de Paris relativas ao ano de 1738, duas notícias sobre o estanho, por Claude-Joseph Geoffroy (1785-1752). Este Geoffroy, chamado também de Geoffroy cadet (caçula) era o irmão mais novo de outro químico célebre, Etienne-François Geoffroy (1672-1731), cognominado Geoffroy ainé (primogênito). A publicação da Academia das Ciências era dividida em duas partes: a primeira, denominada História da Academia Real das Ciências, era mais curta e trazia resumos, não assinados, de muitas das memórias apresentadas à instituição, além de elogios e necrológios; a segunda parte, muito mais extensa, era constituída pelas Memórias, escritas e assinadas pelos autores. No volume considerado, relativo ao ano de 1738, a seção de História apresenta um relato de três páginas intitulado Sobre o Estanho, acerca do trabalho de Geoffroy ${ }^{5}$. Este, contudo, só aparece na íntegra na parte de Memórias, onde recebe o título Do $E_{\text {Estanho }}^{6}$ e se estende por 25 páginas.

Ao começar sua memória, o autor lembra o leitor que o metal de que vai tratar é de uso muito antigo, tendo sido chamado de cassiteron pelos gregos, plumbum album pelos romanos e stannum pelos modernos. Embora ele possa ser encontrado em vários pontos da Europa, como na Alemanha, na Boêmia e na Hungria, o grande fornecedor de estanho fora sempre a Inglaterra, desde o tempo dos fenícios, que o recebiam em Marselha após atravessar toda a Gália. O revisor, na História, acrescenta que é por isso que o arquipélago junto à costa da Cornualha donde provinha o estanho era chamado pelos gregos de Ilhas Cassitéridas. Trata-se de um grupo de cerca de 50 pequenas ilhas próximas a Land's End, na Cornualha, denominadas atualmente Ilhas Scilly ${ }^{7}$. Além do estanho europeu, importava-se também o metal das Índias Orientais, o chamado estanho de Malaca (hoje Malásia), como salienta Geoffroy.

A atenção de Geoffroy está voltada sobretudo para o estanho que se importa da Inglaterra que, em geral, vem em forma de pequenos lingotes denominados salmões. No entanto, aquele país não permite a exportação do estanho puro; conforme suas palavras,

"O estanho não sai da Inglaterra em sua pureza natural ou tal como saiu do forno: há proibições muito rigorosas para transportálo aos países estrangeiros antes que ele tenha recebido a liga de chumbo prescrita pela lei. No entanto, apesar dessas proibições, os curiosos encontram meios de obtê-lo na maior pureza... É a este que eu chamarei de estanho virgem...; o que se chama comumente de estanho fino no comércio já contém chumbo."

Além desses dois tipos de estanho, ele reconhece ainda uma série de outros estanhos, preparados em ligas com outros metais, como o cobre, o zinco, o bismuto e o antimônio. Depois de dizer que já se suspeitava que o estanho contivesse um certo grau de arsênico, prossegue ajuntando:

"A ligação do estanho com as matérias metálicas é tão íntima
RECHERCHES CHIMIQUES SUR'L'ÉTAIN,

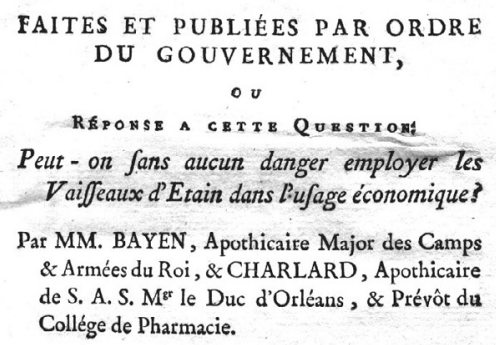

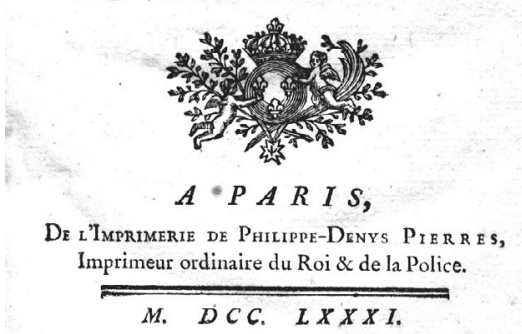

Página de rosto do livro de Pierre Bayen e Louis Charlard, Recherches Chimiques sur l'Étain, publicado em 1781

que elimina toda esperança de separação. Todavia, se for esta porção de arsênico, legitimamente suspeitada no estanho, que faz esta ligação, não parece absolutamente impossível encontrar alguma maneira de desviá-lo para um outro corpo, seja terroso ou metálico..."

Arsênico, ou cal de arsênico, é hoje denominado arsênico ou mais propriamente óxido arsenioso, $\mathrm{As}_{2} \mathrm{O}_{3}$. A substância elementar, que hoje chamamos de arsênio, tinha na época o nome de régulo de arsênico.

A alegação de Geoffroy relativa à presença de arsênico no estanho, contudo, não teve influência, porque, como assinalam Bayen e Charlard em seu livro, "como este químico não se apoiou em nenhum fato bem constatado, sua memória foi impressa e não despertou nenhuma sensação nos espíritos, relativamente ao emprego de vasilhame de estanho".

As opiniões de autores anteriores a Bayen e Charlard divergiam a respeito da presença de arsênico no estanho, e do risco que isso podia representar para a população. Nossos autores são cuidadosos em escrutinar a literatura anterior. Dizem eles: "os médicos do século passado o prescreviam (o estanho) em limalha fina, em fortes doses, nas doenças do fígado e do útero; e o célebre Schulze até reconhece sua inocuidade em sua famosa Dissertação publicada em 1722, e conhecida de todos os praticantes da arte, sob a denominação de Mors in olla (Morte na panela)" ". A referência é ao médico e químico alemão Johann Heinrich Schulze (1687-1744), autor de uma famosa dissertação a respeito da influência dos metais na saúde humana ${ }^{10}$. Schulze inocentava o estanho de qualquer efeito pernicioso, observando que os operários que trabalhavam na sua mineração, redução e transformação não padeciam das doenças comuns a quem fazia operações semelhantes com outros metais.

Bayen e Charlard acrescentam que foi Guillaume Rouelle, o acima mencionado irmão mais velho de seu falecido companheiro de equipe, que introduzira as idéias de Schulze na França. Foi a partir 
da dissertação do químico alemão que ele passara a alertar o público francês sobre os efeitos perniciosos do chumbo e do cobre, sem jamais mencionar o estanho nesse aspecto.

Prosseguindo em sua revisão bibliográfica, os dois químicos franceses relatam que o também químico alemão Andreas Sigismund Marggraf (1709-1782) havia publicado em 1746 e 1747 duas memórias sobre o assunto na Academia de Berlim, das quais a primeira tinha como objetivo demonstrar que certos estanhos contêm e encobrem arsênico. Como a reputação de Marggraf era considerável, começou-se a desconfiar do estanho como um metal seguro para ser usado no vasilhame doméstico. Marggraf cita ainda uma outra opinião anterior em apoio de sua tese, a de seu compatriota Johann Friedrich Henckel (1679-1744), o qual havia descoberto a presença de arsênico no estanho antes dele.

Ferdinand Hoefer, historiador francês da química e autor de influente livro sobre o assunto no século 19, reproduz e comenta boa parte das memórias de Marggraf: ao formar uma liga de estanho e arsênico em proporções conhecidas, o químico alemão alegava que a análise posterior nunca dava o mesmo teor de arsênico que ele havia usado. Sua conclusão o levou a acreditar que era impossível retirar os últimos traços de arsênico do estanho, e era a esta presença de arsênico que ele atribuía a fragilidade do metal ${ }^{11}$.

\section{O USO DO ESTANHO NA FRANÇA DO SÉCULO 18}

Esta era então a situação referente aos possíveis perigos que o estanho poderia apresentar; exatamente em quê, todavia, era o estanho usado na França da segunda metade do século 18? Em séculos anteriores, dizem Bayen e Charlard, o uso do estanho em França havia sido muito mais difundido: o metal era tão comum, "que se viam os aparadores dos habitantes das cidades e as prateleiras dos habitantes do campo repletos de jarros, travessas, pratos, saleiros, potes e copos de estanho. No século passado, igualmente, as comunidades dos mestres picheleiros de estanho, hoje tão decadentes, eram muito ricas.

Todavia, esta baixela, tão estimada por nossos pais, foi em boa parte banida de quase todos os nossos lares; não que se suspeitasse que ela fosse perigosa, mas porque a indústria descobriu uma maneira de tirar melhor partido do estanho, vitrificando-o e aplicando-o sobre a cerâmica.

$A$ arte do esmaltador é muito antiga. Os egípcios, os persas, $e$ sem dúvida os outros povos da Ásia a cultivaram e a comunicaram aos gregos, que a ensinaram aos romanos; se os povos do norte que derrubaram o Império destes últimos nos parecem hoje ter feito todos os esforços para destruir as artes e tudo que elas haviam produzido, é contudo presumível que o esmalte continuou a ser preparado por alguns habitantes da Itália, e que o procedimento para obtê-lo se perpetuou obscuramente até cerca do século dezesseis, quando tomando um impulso brilhante e ainda mais útil, os toscanos, buscando talvez imitar a porcelana que os navegadores traziam da China, encontraram a maneira de esmaltar a cerâmica e de fazer o que nós hoje denominamos faiança." Bayen e Charlard referem-se ao uso do dióxido de estanho como opacificador e formador de esmalte vítreo nas cerâmicas, azulejos e ladrilhos, aplicação esta conhecida desde a antigüidade pré-clássica ${ }^{12}$. E prosseguem: "é pois a Palissy (Bernard Palissy, importante ceramista francês, 1510-1589) que devemos atribuir, se não a invenção, pelo menos a primeira imitação feita entre nós da faiança, tipo de baixela que, aperfeiçoandose dia a dia, substituiu a de estanho em quase todas as nossas casas. A beleza desse material e sobretudo sua limpeza, que só exige poucos cuidados para sua manutenção, mereceu-lhe, apesar de sua fragilidade, a preferência sobre o estanho, embora se estivesse muito longe, como já se disse, de atribuir ao estanho ou mesmo de se sus- peitar nele qualquer qualidade nociva à economia animal." O estanho, porém, não havia desaparecido do uso quotidiano dos franceses. Mais adiante eles se apressam a esclarecer este aspecto:

"Mas se só raramente nos servimos de travessas, de pratos e de sopeiras de estanho, se as bilhas de água feitas deste metal são pouco conhecidas mesmo entre as pessoas de fortuna a mais mediocre, todavia não se deixa de empregá-lo num grande número de utensílios, aos quais seria preciso renunciar completamente se se constatasse que este metal fosse pernicioso. Vê-se nos negócios e nas cozinhas dos ricos, em todos os que preparam e vendem comestiveis prontos para serem servidos, nos confeiteiros, nos limonadeiros, etc. etc., grandes bandejas de estanho, tinas de tamanhos diferentes, sorveteiras, etc. etc. Muitos particulares possuem cântaros de estanho; todas as partes internas dos alambiques e suas serpentinas são igualmente feitas de estanho, assim como todas as medidas usadas para a venda de líquidos. Não é raro ver nas grandes residências, até nos palácios de nossos reis, grandes frascos de estanho servindo para transportar a água destinada à bebida diária; as casas religiosas, os habitantes do campo ainda se servem de travessas e de pratos de estanho. Enfim, este metal recobre toda a baixela de cobre de uso das cozinhas, e por meio de uma pequena camada do primeiro acredita-se estar ao abrigo das más qualidades do segundo"13.

O estanho existente no comércio da França podia ser agrupado em três categorias, de acordo com Bayen e Charlard: a primeira, compreendia o estanho puro, tal como sai das fundições; a segunda, constituía as diferentes ligas contendo outros metais, preparadas nas mesmas fundições; finalmente, a terceira classe era a do estanho trabalhado pela comunidade dos picheleiros, que deviam se conformar aos regulamentos estabelecidos no passado, mas que haviam deixado de ser seguidos à risca. $\mathrm{O}$ estanho puro vinha da Inglaterra, como já se disse, e na sua falta, das Índias Orientais. Os estanhos tidos no comércio como os mais puros eram em geral os estanhos ingleses, que eram denominados justamente estanhos puros ou primitivos. Sua exportação da Inglaterra se fazia sob a forma de pequenas amostras. No entanto, o grande volume de estanho inglês que chegava à França estava na forma de grandes lingotes de 300 libras, chamados de grandes salmões. Ele era vendido no varejo sob a forma de varas de seção triangular com um pé e meio de comprimento.

\section{PRIMEIROS ESTUDOS DE BAYEN E CHARLARD: ENSAIOS DE CALCINAÇÃO DO ESTANHO PURO}

Para estudar o comportamento químico do estanho puro, os dois químicos lançaram mão de quatro amostras diferentes de estanho primitivo: de Banca e Malaca no oriente, da Inglaterra e de porções adquiridas no comércio de Paris sob o nome de estanho doce. A combustão ao ar das quatro amostras desse estanho primitivo se processava sempre da mesma maneira, resultando na formação de um pó branco, chamado de cal ou flores de estanho, modernamente dióxido de estanho.

Em seguida, Bayen e Charlard resolveram estudar o efeito do fogo sobre os estanhos primitivos mantidos num recipiente fechado: pequenos pedaços de estanho de Banca de 4 a 5 linhas ${ }^{14}$ de comprimento e uma linha de diâmetro foram postos numa retorta de vidro, que foi vedada hermeticamente. O conjunto foi levado para um forno onde sofreu aquecimento intenso por oito horas. Após esse tempo, verificou-se que apenas uma pequena parte do estanho se havia calcinado. Uma pequena parte de cal ficava agarrada ao pescoço da retorta, o que eles atribuíram à sublimação seguida de condensação. Para oito onças de metal verificava-se, após o experimento, que seu peso diminuíra em apenas um grão ${ }^{14}$. Em termos e unidades modernas, pode-se dizer que de 244,48 g de metal utilizado, apenas $0,05 \mathrm{~g}$ se calcinaram. O experimento foi repetido com os outros tipos de estanho primitivo, 
com resultados análogos. Um pormenor interessante que eles relatam é que, após o aquecimento, o estanho, assim como acontecia com outros metais, como o chumbo, o zinco e o bismuto, apresentava um brilho iridescente dourado ou semelhante ao pescoço de uma pomba. Este é um fenômeno óptico interessante, já observado anteriormente, como eles assinalam, mesmo por químicos que nem de longe seriam postos entre os pesquisadores da pedra filosofal ${ }^{15}$.

As conclusões deste primeiro conjunto de experimentos foram:

1. a quantidade de cal obtida independe da quantidade de estanho usada;

2. a cal volátil, isto é, a primeira porção, que se sublimava e condensava no pescoço da retorta, só era produzida no início da reação;

3. mesmo usando um fogo dos mais violentos por $8 \mathrm{~h}$, não se produzia mais cal. É de notar-se que a retorta de vidro ficava completamente deformada ao final de cada experimento.

Marggraf, que havia executado experimentos semelhantes, supunha que o pó branco aderido ao colo da retorta fosse arsênico, e não cal de estanho, mas a quantidade era tão diminuta que ele não pudera analisá-la para decidir a questão. Bayen e Charlard lhe contrapõem o seguinte: "a quantidade é pequena, sem dúvida; mas como a centésima parte de um grão de arsênico posta sobre uma brasa era suficiente para reconhecer esta substância sem qualquer equívoco, acreditamos que devíamos fazer todos os esforços para mudar as suspeitas de Marggraf em certeza, e se por acaso nos fosse impossível decidir por experiências certas de que natureza era o sublimado, ao menos não devíamos desprezar nada, para nos assegurarmos se era ou não arsênico, e por isso mesmo, levantar as dúvidas de Marggraf "16.

$\mathrm{O}$ arsênico, posto sobre uma brasa, produz um cheiro extremamente desagradável e muito forte, que lembra o cheiro de alho, mas bem mais intenso. Este cheiro pode ser percebido mesmo em diminutas concentrações, mas não foi sentido pelos dois químicos. Em nenhum dos quatro experimentos realizados com o estanho primitivo puderam os dois químicos perceber qualquer traço de cheiro no suposto resíduo arsenical.

Cadet de Gassicourt havia descoberto em 1760 que ao destilar uma mistura de quantidades iguais de óxido arsenioso e acetato de potássio produzia-se um líquido espesso e castanho, fortemente fumegante, com um cheiro especialmente desagradável. No século 19 o líquido de Cadet veio a inspirar por largo tempo o tema de pesquisa do químico alemão Robert Wilhelm Bunsen (1811-1899). Bunsen descobriu vários compostos orgânicos de arsênio, todos com o mesmo cheiro desagradável e alta toxidez. Esses compostos apresentavam uma química complexa e tinham em comum a presença de grupos orgânicos ligados ao arsênio, principalmente o grupamento cacodila, $\left(\mathrm{CH}_{3}\right)_{2} \mathrm{As}$. $\mathrm{O}$ mais famoso desses compostos organoarseniosos era o óxido de cacodila $\left(\mathrm{CH}_{3}\right)_{2} \mathrm{AsOAs}\left(\mathrm{CH}_{3}\right)_{2}$. O nome cacodila, do grego para mau cheiro, foi sugerido por Jöns Jacob Berzelius (1779-1848) $)^{17}$.

Dando prosseguimento a seus experimentos, Bayen e Charlard misturaram o presumido sublimado branco de arsênico com miolo de pão e o deram a um cão, que o comeu sem qualquer efeito. A dose de pó branco que o cão comeu correspondia a 1 grão, que seria mais que suficiente para matá-lo, caso fosse arsênico.

\section{ENSAIOS DO ESTANHO COM A ÁGUA RÉGIA}

A seqüência seguinte de experimentos diz respeito à dissolução do estanho em vários solventes. Mais uma vez a autoridade de Marggraf é invocada, e eles resolvem seguir o procedimento indicado pelo químico alemão.
Em primeiro lugar, procede-se à dissolução do estanho em água régia. Esta foi preparada como ensinava Marggraf, dissolvendo meia dracma de sal amoníaco (cloreto de amônio) em uma dracma ${ }^{18}$ de ácido nítrico. Em seguida, dissolve-se meio escrópulo de estanho em quatro onças de água régia. Observa-se a formação de um pó branco. Adicionando-se mais estanho, o pó branco se dissolve e obtém-se uma solução incolor, sem sedimento. Se a solução for aquecida lentamente num banho de areia, deixando evaporar o líquido, produzem-se vapores brancos e aparecem cristais, que se formam em grande quantidade ao resfriar-se o frasco. Estes cristais seriam arsênico puro (na realidade, tetracloreto de estanho hidratado, $\mathrm{SnCl}_{4} .5 \mathrm{H}_{2} \mathrm{O}$ ). Bayen e Charlard seguiram à risca o método de Marggraf, utilizando separadamente cada um dos quatro estanhos primitivos de que dispunham. Em todos os experimentos obtiveram os belos cristais brancos, só que eles não deram teste positivo para arsênico. Os químicos franceses dizem que "não nos desencorajamos, e esta experiência foi repetida oito vezes para cada estanho, mas sempre infrutiferamente". E logo a seguir, com talvez uma ponta de disfarçada ironia:

"Atormentamo-nos cruelmente quando, ao seguir um químico tal como Marggraf, não se consegue obter os resultados que ele anuncia. Acreditamos então que era preciso repetir mais duas vezes o mesmo trabalho com o estanho de Malaca, que aquele célebre homem diz ter fornecido uma quantidade notável de arsênico, sem todavia fixá-la; mas estas duas novas operações nada nos ensinaram, e foram tão inúteis como as primeiras.

É natural concluir que nossos quatro estanhos não nos forneceram arsênico pela razão que eles não o continham; mas esta conclusão, parecendo-nos um pouco precipitada, não podíamos decidir abandonar nossas pesquisas sobre um assunto tão importante. Então, sem sequer presumir que o arsênico não existia nesses estanhos, acreditamos dever recorrer a experiências comparativas, tomando para este efeito a iniciativa de introduzir nesses mesmos estanhos o arsênico em doses conhecidas e graduadas, desde 1/16 até 1/1200, e ir até mesmo mais longe se fosse necessário"19.

Neste ponto eles fazem uma pausa para esclarecer o que se quer dizer com a palavra arsênico, a qual, ao que parece, havia sido confundida por Marggraf:

"Em geral as cais metálicas não se unem aos metais, a menos que eles encontrem na fusão uma matéria própria a operar sua solução. Marggraf procurou, contudo, unir o estanho ao arsênico propriamente dito, isto é, a uma cal metálica"20. Marggraf não havia dado muita atenção a este problema químico fundamental e fez o experimento com o estanho e a cal de arsênio. Como resultado, informam-nos os químicos franceses, obteve cal de estanho e régulo de arsênico (arsênio elementar). Ocorreu o que hoje se denomina uma reação de oxirredução, com a redução do arsênio e a oxidação do estanho.

Aos poucos a crítica a Marggraf perde a polidez inicial e se torna mais dura: "Acreditamos dever abandonar o procedimento (de Marggraf), substituindo-o por um outro mais de acordo com os princípios de uma química sã ${ }^{, 21}$.

\section{PREPARAÇÃO DE LIGAS DE ESTANHO E SEUS ENSAIOS COM A ÁGUA RÉGIA}

Iniciando um novo procedimento, Bayen e Charlard prepararam por aquecimento uma liga a partir de 2 gros de régulo de arsênio e 3 onças e 6 gros de estanho. A liga assim obtida contém 1/16 de arsênio, com pouquíssimo material perdido por sublimação. Esta liga é bem pouco maleável e, ao fundir, torna-se pastosa e escoa bem numa lingoteira, ao contrário do estanho. A liga fundida desprende um forte cheiro de arsênico (ou seja, de algum produto relacionado aos compostos cacodílicos). Em ensaios subseqüentes eles prepararam 
ainda quatro outras ligas, variando o teor de arsênio: a liga com 1/32 de arsênio também se mostrou muito frágil, como a primeira; o mesmo ocorreu com a liga com 1/64 de arsênio. Quando o teor de arsênio caiu para 1/128 a liga era um pouco mais dútil, mas os lingotes finos só se dobravam com esforço, e se quebravam facilmente ao dobrálos. Finalmente, a liga com $1 / 256$ de arsênio era mais dútil, mas mesmo assim ainda não se prestava a ser trabalhada pelos picheleiros.

O ensaio seguinte consistiu em determinar o efeito da água régia sobre as cinco ligas precedentes. Dissolvendo-se 36 grãos da primeira liga, preparada na proporção de 1/16 de arsênio, com meia onça de água régia, obteve-se uma solução incolor e um precipitado constituído por 2 gros de um pó negro. Este pó, após ser lavado e secado, foi posto sobre uma brasa, produzindo uma fumaça cujo odor corresponde àquele obtido com o arsênio puro. Este procedimento mostrou que o ataque pela água régia havia retirado da liga todo o arsênio utilizado em seu preparo (2 gros). O mesmo resultado foi obtido para as outras quatro ligas, mantendo-se as proporções quantitativas respectivas.

Num passo seguinte, decidiu-se estender o método a concentrações ainda menores de arsênio, produzindo-se ligas com as proporções respectivas de 1/512, 1/1024 e 1/2048 de arsênio. Os resultados foram análogos, embora fosse progressivamente mais difícil ver as partículas de arsênio elementar ao final do processo. Para facilitar essa visualização, em cada caso eles faziam a experiência com a liga e com estanho puro, para poder comparar o aspecto final.

Após esses experimentos, os autores dão seu veredicto e criticam duramente Marggraf: definitivamente o estanho puro não contém arsênio. Ou Marggraf usou estanhos muito impuros ou incorreu em grave erro. O estanho em liga com o arsênio tem um aspecto tão diferente do metal puro que seria impossível a quem trabalha com ele não reconhecer a diferença: "sua aspereza, as grandes facetas que ele apresentaria nas fraturas e mesmo em sua superfície o teriam colocado na classe dos semi-metais"22.

Consideravam-se semi-metais, no século 18, algumas substâncias com propriedades semelhantes aos metais, que eram, porém, sublimáveis ou com baixa ou nenhuma dutilidade. As listas variavam conforme os químicos, e os critérios não eram rígidos. Em geral incluíam o antimônio, o arsênio, o bismuto, assim como o mercúrio. Também podiam conter o cobalto e o zinco, e, mais tarde, também o níquel.

\section{ENSAIOS COM O ÁCIDO CLORÍDRICO}

Em seguida, Bayen e Charlard decidem estudar o efeito do ácido marinho (clorídrico) sobre o estanho. Como eles mostrarão, o ácido marinho dá resultados mais decisivos que a água régia.

Antes de proceder às experiências, o ácido marinho foi retificado para retirar o ferro que o torna amarelo. Após o procedimento, que é descrito em pormenor, obtiveram um ácido marinho fumante e incolor. Este ácido dissolve o estanho, mas, ao contrário da água régia, é preciso aquecimento para que a reação se processe. Num matraz de pescoço longo tapado posteriormente com uma rolha de papel, pôs-se a mistura, consistindo em 4 onças de pedacinhos de estanho puro de Banca e 12 onças de ácido de sal marinho concentrado; o conjunto foi aquecido vivamente sobre banho de areia, produzindo-se uma efervescência intensa. $\mathrm{O}$ aquecimento continuou por dois dias e, ao final, restava uma solução incolor (de cloreto estanoso, diríamos hoje). A operação foi em seguida repetida com ligas de arsênio e estanho na proporção 1/128. Foram feitas quatro ligas nesta proporção, uma com cada uma das quatro amostras distintas de estanho primitivo disponíveis. Nestes quatro últimos ensaios obteve-se sempre um pó negro com uma massa entre 17 e 18 grãos, correspondente à massa de arsênio introduzida no estanho. Sua nature- za arsenical foi identificada encostando $1 / 4$ de grão numa brasa: imediatamente se desprendeu o cheiro característico do arsênio, lembrando o cheiro de alho.

Para mostrar sua meticulosidade, os dois pesquisadores fizeram ainda mais duas ligas, nas proporções de 1/675 e 1/2304 partes de arsênio em relação ao estanho, e as testaram com o ácido marinho. Em ambos os casos o resultado foi o mesmo que nos ensaios anteriores.

\section{ENSAIOS COM O ÁCIDO NÍTRICO}

A etapa seguinte foi fazer testes com o ácido nítrico, naquela época ainda denominado nitroso. Eles bem conheciam o diferente modo de ação do ácido nítrico em comparação com os anteriores, assim como a controvérsia que circundava o modo de ação deste ácido: "a ação viva do ácido nitroso (sic) sobre o estanho é conhecida; sabe-se mesmo que este agente poderoso, parecendo devorar este metal, todavia não o dissolve, que ao contrário o calcina e reduz a uma espécie de massa branca. Como este procedimento não foi investigado mais a fundo, é mais ou menos tudo o que se encontra nos autores que já citamos"23. Em simbologia moderna podemos expressar a reação como:

$4 \mathrm{HNO}_{3 \text { conc. }}+\mathrm{Sn} \rightarrow \mathrm{SnO}_{2}+4 \mathrm{NO}_{2}+2 \mathrm{H}_{2} \mathrm{O}$

Em nota de rodapé, todavia, eles discutem o problema das reações do ácido nítrico, a partir de uma observação de dois "célebres irmãos a quem a química francesa tanto deve", evidentemente os irmãos Rouelle, mencionados no início deste artigo. Estes, contrariamente à opinião corrente, como a de Baumé, haviam conseguido dissolver o estanho em ácido nítrico usando uma solução extremamente diluída do ácido. Bayen e Charlard afirmam que também eles conseguiram executar essa dissolução usando um ácido diluído e fazendo a reação de forma bem lenta e sem permitir a elevação da temperatura. Eles dizem ainda que esta reação é difícil de executar no verão, mas pode ser feita sem grandes problemas no inverno. Podemos descrever modernamente a reação da seguinte forma:

$$
10 \mathrm{HNO}_{3 \text { dil. }}+4 \mathrm{Sn} \rightarrow 4 \mathrm{Sn}\left(\mathrm{NO}_{3}\right)_{2}+\mathrm{NH}_{4} \mathrm{NO}_{3}+3 \mathrm{H}_{2} \mathrm{O}
$$

Embora a reação acima seja aceita por autores modernos, estima-se que a composição do sal $\mathrm{Sn}\left(\mathrm{NO}_{3}\right)_{2}$ seja mais complexa que esta fórmula simples faz supor ${ }^{24}$.

Esta última reação é, porém, uma reação especial, quando se usa ácido nítrico bastante diluído, e não aquela reação mais comum, que produz o precipitado branco de cal de estanho $\left(\mathrm{SnO}_{2}\right)$.

Fazendo agora a reação entre 2 onças e meia de cada um dos quatro estanhos primitivos e o ácido nítrico concentrado, Bayen e Charlard obtiveram nos quatro casos a mesma quantidade de cal branca, a menos de pequenos erros experimentais, que eles são cuidadosos em mostrar. As reações completas levaram 15 dias para se completar, e as cais foram aquecidas e dessecadas, com sua cor passando a levemente cinza. As águas-mães eram límpidas e sua acidez quase nula, de acordo com os testes feitos. Evaporadas em banho-maria, reduziram-se a quatro onças sem perder sua transparência. Nesta forma concentrada a acidez reapareceu, isto é, foi possível detectála, e apareceu o cheiro de espírito de nitro $\left(\mathrm{NO}_{2}\right)$. Continuando a evaporação até a secura, obteve-se um sal branco. Este sal, posto sobre uma brasa, incha, perde sua umidade e arde, fundindo-se como o nitro (nitrato de potássio), dando uma chama branca e espessa. Este sal é novo e eles o chamam de sal "estano-nitroso". Nenhum traço de arsênio é detectado. Aquecendo o sal estano-nitroso num matraz fechado, ele dá origem a vapores brancos que lembram o 
"licor fumante de Libávio". Este "licor" é o tetracloreto de estanho, líquido incolor que, em contato com a umidade, reage dando uma fumaça muito fina de pó de $\mathrm{SnO}_{2}$ :

$\mathrm{SnCl}_{4}+2 \mathrm{H}_{2} \mathrm{O} \rightarrow \mathrm{SnO}_{2}+4 \mathrm{HCl}$

O resíduo obtido por Bayen e Charlard da água-mãe da reação poderia resultar de uma reação entre o nitrato de estanho (II) e o nitrato de amônio, formados ao final do ataque ao estanho, quando a concentração de ácido nítrico já era bem pequena, de acordo com a penúltima equação acima. Supondo que seja assim, o aquecimento da mistura poderia ser descrito pela equação:

$\mathrm{Sn}\left(\mathrm{NO}_{3}\right)_{2}+2 \mathrm{NH}_{4} \mathrm{NO}_{3} \rightarrow \mathrm{SnO}_{2}+6 \mathrm{NO}+4 \mathrm{H}_{2} \mathrm{O}$

\section{ENSAIOS COM OS ÁCIDOS SULFÚRICO E ACÉTICO}

O próximo passo no programa de pesquisa de Bayen e Charlard foi estudar o efeito do ácido vitriólico (sulfúrico) e do vinagre destilado sobre os quatro estanhos primitivos.

$\mathrm{O}$ ataque ao estanho foi conduzido com o ácido vitriólico fervente, observando-se a produção de ácido sulfuroso (dióxido de enxofre) e a produção de uma solução incolor muito límpida enquanto estiver quente. Ầ medida que esfria, a solução forma uma massa gelatinosa higroscópica. Esta massa gelatinosa contém estanho, o que foi demonstrado fazendo sua precipitação com álcali fixo (carbonato de potássio). Finalmente, pela adição de água à massa gelatinosa, precipita-se lentamente uma cal branca de estanho (dióxido de estanho). Podemos representar essas reações de acordo com as equações dadas abaixo ${ }^{25}$

Reação do estanho com o ácido vitriólico, produzindo um gel:

$\mathrm{Sn}+2 \mathrm{H}_{2} \mathrm{SO}_{4}+\mathrm{n} \mathrm{H}_{2} \mathrm{O} \rightarrow \mathrm{SnO}_{2} \cdot\left(\mathrm{H}_{2} \mathrm{O}\right)_{\mathrm{n}}+2 \mathrm{SO}_{2}+2 \mathrm{H}_{2} \mathrm{O}$

Teste com o álcali fixo:

$\mathrm{SnO}_{2} \cdot\left(\mathrm{H}_{2} \mathrm{O}\right)_{\mathrm{n}}+\mathrm{K}_{2} \mathrm{CO}_{3} \rightarrow \mathrm{K}_{2} \mathrm{SnO}_{3} \cdot 3 \mathrm{H}_{2} \mathrm{O}+\mathrm{CO}_{2}+(\mathrm{n}-3) \mathrm{H}_{2} \mathrm{O}$

Precipitação lenta da cal de estanho pela destruição do gel:

$\mathrm{SnO}_{2} \cdot\left(\mathrm{H}_{2} \mathrm{O}\right)_{\mathrm{n}} \rightarrow \mathrm{SnO}_{2} \cdot \mathrm{H}_{2} \mathrm{O}+(\mathrm{n}-1) \mathrm{H}_{2} \mathrm{O}$

A reação com o vinagre é a mais lenta e menos intensa de todas. Foi preciso deixar as quatro amostras dos estanhos primitivos em matrazes contendo vinagre destilado durante todo o verão e o outono à temperatura ambiente para que se pudesse observar alguma reação, embora pouco intensa. Apenas uma parte do estanho reagira, após todo aquele tempo, dando um precipitado branco difícil de caracterizar, que eles denominam sal de estanho acetoso. Apesar de toda a dificuldade, nenhuma das reações executadas deixa de ter todas as massas de reagentes e produtos pesadas cuidadosamente.

\section{CONCLUSÕES DE BAYEN E CHARLARD ACERCA DA PRESENÇA DE ARSÊNIO NOS ESTANHOS PRIMITIVOS. ENSAIOS SOBRE O ESTANHO INGLÊS DO COMÉRCIO}

Após todos esses ensaios, Bayen e Charlard concluem que, contrariamente à opinião de Marggraf e de outros químicos, o estanho puro definitivamente não contém arsênio. Resta, no entanto, determinar se os estanhos usados no comércio não poderiam estar contaminados com aquela substância nociva. Vem então a segunda seção da obra, onde eles apresentam o exame do estanho inglês conhecido no comércio sob o nome de grandes salmões e bastões.
Inicialmente, é feita uma descrição do estanho inglês, como já se mencionou no início deste artigo. Na análise com ácido nítrico, o resultado é semelhante àquele dos estanhos puros, com a descoberta de um pequeno teor de sal azul, que eles reconhecem como sendo o nitrato de cobre. Além deste sal, também identificam a presença de nitrato de zinco, concluindo então que o estanho da Cornualha tem adição de latão (liga de cobre e zinco) em sua formulação. Eles não encontraram nem chumbo nem arsênio. $\mathrm{O}$ zinco, segundo eles, tinha a função de aumentar a dureza e também restituir ao estanho o brilho argênteo que o cobre lhe subtraía.

$\mathrm{O}$ exame do estanho inglês com a água régia veio trazer uma surpresa: a dissolução do metal produzia também pequena quantidade de arsênio, que dava teste positivo na brasa, apesar das quantidades diminutas obtidas. Resultado análogo deu o teste do estanho inglês com o ácido marinho, o qual produziu pequena quantidade de um pó preto que, ao ser posto sobre uma brasa, exalou o cheiro característico dos compostos de arsênio. Os testes com os estanhos ingleses foram repetidos com grande meticulosidade, chegando-se à conclusão de que os estanhos ingleses tinham um pequeno teor de arsênio, que variava de $1 / 576$ a 1/3152, com uma média em 1/762.

Mais à frente eles decidem estudar o efeito do ácido nítrico sobre o régulo de arsênico (arsênio elementar), concluindo pela experiência que o ácido nítrico, tanto a quente como a frio, dissolve o régulo, dando uma solução incolor. Conseqüentemente, este não é um bom teste para saber se o estanho contém ou não arsênio.

Um procedimento semelhante é executado com o ácido marinho, que só dissolve o régulo de arsênico a quente e, mesmo assim, só parcialmente. A solução leva, por evaporação, a um sal amarelado, que dá resultado positivo para arsênio no teste da brasa.

Embora com água régia diluída a reação com as ligas de estanho houvesse produzido uma solução límpida e a precipitação do arsênio, ao fazer a reação diretamente com o arsênio puro em água régia concentrada a quente, o material se dissolveu completamente em um quarto de hora. Ao se usar, contudo, uma água régia diluída, a reação foi bastante lenta, só mostrando os primeiros sinais de formação de um novo material ao cabo de oito dias. Uma parte do arsênio se dissolve, ocorrendo também a formação de um pó branco de cal de arsênio. A reação com a água régia é, por sua complexidade, descartada como incapaz de dar uma boa caracterização para o arsênio.

A partir destas últimas três reações, Bayen e Charlard concluem que o melhor reagente para caracterizar o arsênio é efetivamente o ácido marinho.

\section{O ESTANHO À VENDA SOB A FORMA DE OBJETOS ACABADOS}

A terceira seção do livro de Bayen e Charlard examina o estanho trabalhado e posto à venda na França sob a forma de utensílios pelos mestres picheleiros. Suas análises lhes permitirão dizer que os pratos de estanho comprados no comércio de Londres são "feitos de um estanho bem superior a tudo que se poderia comprar em Paris neste gênero" ${ }^{26}$. No entanto, eles contêm régulo de arsênio na proporção média de 1/708, enquanto em Paris a proporção é de 1/864. Os ingleses, ao contrário dos franceses, só ajuntam um pouco de bismuto ao estanho, fazendo uma liga bem diferente da francesa. Nesta se encontra freqüentemente chumbo, o que não ocorre nos estanhos ingleses. Como o estanho das Índias é puro, sua mistura com o estanho inglês é responsável pelo menor teor de arsênio no estanho francês. Os materiais que os mestres de Paris utilizam para formar ligas com o estanho são: $1^{\circ}$, o cobre vermelho ou roseta; $2^{\circ}$, o bismuto ou estanho vítreo; $3^{\circ}$, o zinco, sozinho ou unido ao cobre vermelho, formando o latão ou cobre amarelo; $4^{\circ}$, o chumbo; $5^{\circ}$, o régulo de antimônio (antimônio elementar). Aqui eles voltam a citar Geoffroy, 
em cuja memória ${ }^{5}$ já eram apontados estes componentes do estanho parisiense, os quais eram adicionados em decorrência das propriedades mecânicas ou de aspecto que se quisesse dar ao produto. É possível purificar quimicamente o estanho, retirando-lhe impurezas como cobre ou zinco, e os dois mostrarão mais à frente como se pode fazer isso. No entanto, o preço dessas operações não compensa sua execução. Por isso, os picheleiros, quando desejam modificar a composição do estanho, preferem misturá-lo com estanho puro, diluindo assim as impurezas. A isso se chama liga por subtração.

O cobre é adicionado ao estanho para conferir-lhe mais dureza, e é utilizado numa proporção entre 1 e 2,5 libras por quintal de estanho $(1$ quintal $=100$ libras $)$. Tanto o bismuto como o zinco fazem reaparecer a cor argêntea do estanho contendo cobre, assim como aumentam ainda mais a dureza que o estanho já recebera do cobre. O bismuto é adicionado na proporção de 1 a 1,5 libras por quintal, ao passo que o zinco não ultrapassa o teor de $0,5 \%$. Todavia, o bismuto não é o favorito para os mestres picheleiros, segundo eles porque também torna o estanho quebradiço. Bayen e Charlard suspeitam de um outro fator, que é o preço do bismuto, mais caro que o zinco, que é o aditivo preferido neste caso. Ademais, como o bismuto tem afinidade química com o chumbo, isso leva à suspeita de que também compartilhe suas qualidades nefastas.

As ordenações do reino proibiam o uso do chumbo no chamado estanho fino, isto é, o estanho de melhor qualidade. O chumbo só podia entrar no estanho comum, bem mais barato. Tradicionalmente os mestres picheleiros ajuntavam 7 ou 8 libras de chumbo a um quintal de estanho fino para fazer o estanho comum.

Com relação ao antimônio, as análises de Bayen e Charlard não evidenciaram seu uso nos estanhos usados no vasilhame disponível comercialmente. Sua opinião é que os mestres não gostam desse material, que tende a tornar o estanho áspero e quebradiço. $\mathrm{O}$ estanho com antimônio é utilizado apenas em colheres muito frágeis, de uso da população mais pobre.

Enfim, o bom estanho fino é aquele que contém 100 libras de estanho puro de Banca ou Malaca, de 2 a 2,5 libras de cobre, algumas onças de zinco ou de bismuto e nada de chumbo, além da pequena quantidade de arsênio, da ordem de 1/576. Já o estanho comum pode também conter chumbo, num teor de 6 a $8 \%$.

Há um outro tipo de estanho que também não escapou ao escrutínio dos químicos franceses, o chamado estanho velho. Conforme dizem eles, "embora o uso do estanho se haja tornado muito menos freqüente entre nós que antigamente, a quantidade que se encontra no reino não deixa de ser ainda muito grande. As casas religiosas de ambos os sexos, os colégios, a maioria das comunidades, os hospitais não utilizam outro tipo de baixela; são poucas as vendas de espólios em que ele não se encontre, ou em baixela de mesa ou pelo menos em utensílios de cozinha e escritório. Que quantidade de medidas para líquidos não é necessária em uma cidade como Paris e em um reino como a França! Ora, todas essas medidas, da bilha à medida para vinho, são de estanho; os recipientes para os sorvetes, os capitéis de alambiques, as cucúrbitas a banho-maria, as serpentinas são todos igualmente deste metal; enfim, tanto nesta capital como nas outras cidades do reino, vê-se entre os cidadãos, ao adquirir por seu trabalho uma certa abastança, alguma baixela de estanho, e ele também se encontra amiúde entre os habitantes do campo"27.

$\mathrm{O}$ estanho antigo era muito cobiçado pelos mestres para ser fundido, porque não continha qualquer traço de chumbo. Isto se devia, segundo os autores, a um relaxamento geral ao longo dos últimos 60 anos, que permitira uma piora gradual na qualidade do estanho novo disponível. Ao tempo do livro de Bayen e Charlard (1781), havia, segundo eles afirmam, estanho vendido como fino que continha 5, 6, 7 e até 8 libras de chumbo por quintal, e estanho comum com 15, 20 e mesmo 25 libras de chumbo.

\section{COMO PURIFICAR QUIMICAMENTE UM ESTANHO ALTERADO?}

Como se poderia purificar quimicamente um estanho corrompido? Bayen e Charlard decidem investigar os meios possíveis para reconhecer as substâncias ligadas ao estanho e separá-las dele.

Citando Geoffroy ${ }^{6}$, dizem que aquele químico simplesmente notara que o estanho puro calcinado dava uma cal muito branca, ao passo que aqueles obtidos do estanho fino e do comum, assim como dos salmões ingleses, produziam resíduos de calcinação cujas cores tanto mais se distanciavam do branco puro quanto maior fosse o teor do componente em liga com o estanho. Para Bayen e Charlard, contudo, este é um método muito dispendioso e inútil, porque só se observam matizes na cor da cal de estanho. Não tem nenhum valor quantitativo.

Decidem então estudar formas práticas de retirar do estanho os metais que o impurificam. De acordo com seu procedimento usual, sempre metódico, eles desenvolvem ensaios para cada metal e os descrevem com a meticulosidade costumeira.

Em primeiro lugar, vem a discussão da retirada do cobre do estanho pela água régia. Para isso, tomam 100 grãos de uma massa de estanho puro em liga com $1,5 \%$ de cobre, reduzida a uma lâmina muito delgada que se dividiu em três partes iguais. A primeira foi posta numa cápsula de vidro com 3 gros de água régia. Não se tardou a ver uma efervescência e a lâmina desapareceu. Ajuntando-se a segunda lâmina o mesmo se repetiu, e assim também com a terceira lâmina. O líquido resultante ficou verde, mas muito límpido. Se, nesta solução, se introduzir a extremidade de uma lâmina de estanho puro, nela se deposita imediatamente uma película de cobre, que se destaca agitando-se a lâmina num frasco com água. O processo pode ser repetido até que o cobre não mais se deposite na lâmina. Assim se obtém 1,5 grão de cobre, isto é, a quantidade precisa que havia sido introduzida nos 100 grãos de estanho puro. Se se acrescentar à mesma quantidade de água régia 3 gros de água destilada, a dissolução das lâminas é lenta e sem aquecimento; só o estanho se dissolverá e o cobre permanecerá intacto, sob a forma de um pó quase negro, que pesará igualmente 1,5 grão. Com o ácido do sal marinho o resultado é idêntico a este último caso, sendo o estanho dissolvido e o cobre restando intacto.

Em seguida eles tratam da separação do bismuto e do zinco. Com o bismuto, as duas operações precedentes descritas para o cobre se repetem, com a diferença que a solução é incolor e o bismuto se precipita em cada caso como um pó negro. Contudo, aqui as reações são muito mais lentas. Quando se utiliza o estanho contendo cobre e bismuto, o pó que se obtém contém os dois metais (para eles um metal, o cobre, e um semi-metal, o bismuto). Para separá-los, ajuntase sobre o pó seco uma quantidade suficiente de álcali volátil líquido (solução de amônia), que retirará o cobre sem tocar no bismuto. Aqui eles estão utilizando a conhecida propriedade exibida pelo cobre de formar facilmente um complexo com a amônia. Eles terminam esta parte dizendo: "um instante de evaporação será suficiente para dissipar todo o sal volátil e fazer aparecer o cobre na forma de cal, de sorte que essas duas substâncias poderão separadamente ser submetidas à balança" 28 .

A separação seguinte a ser discutida é a do chumbo. Aqui a água régia não é conveniente: embora ela não tenha uma ação bem marcada sobre o chumbo, mesmo sob ebulição, ela o dissolve rapidamente quando ele está ligado a 3 partes de estanho, até a frio. O mesmo acontece se se fizer o seguinte: pedaços de chumbo não se dissolvem em água régia quente, mesmo após $3 \mathrm{~h}$ de fogo; no entanto, introduzindo-se no matraz pedaços de estanho, ambos os metais logo se dissolvem.

$\mathrm{O}$ ácido marinho dissolve o chumbo e forma um sal que cristaliza ao resfriar-se a solução, mas o resultado não é bom. Contudo, o 
ácido nítrico vem a mostrar-se um excelente agente para este ensaio. O ácido nítrico reage com o estanho puro de forma enérgica, produzindo uma cal branca que, lavada e secada, forma uma espécie de geléia semi-transparente. Evaporando a água de lavagem, obteve-se uma pequena quantidade de um sal que foi denominado estanonitroso, como já se descreveu anteriormente neste artigo. Este sal tem a propriedade de se incendiar quando é aquecido. Se o estanho tratado com ácido nítrico contiver cobre, zinco ou chumbo, eles permanecerão em solução. Só o bismuto não se dissolve, a não ser que se adicione uma certa quantidade de água. No entanto, o chumbo é aqui o mais importante de investigar. Evaporando a solução em banho-maria, será possível precipitar um nitro à base de chumbo (nitrato de chumbo).

Um grande número de ensaios adicionais é ainda descrito pelos dois autores, que querem demonstrar aos leitores a justeza de sua química, tanto do ponto de vista qualitativo como quantitativo.

\section{O ARSÊNIO NO ESTANHO É PERIGOSO À SAÚDE?}

Depois de todas essas demonstrações complementares, chegamos à quarta seção do livro, na qual eles vão finalmente responder à questão inicialmente proposta: pode-se sem nenhum perigo usar o vasilhame de estanho?

Em primeiro lugar, há que considerar de que tipo de estanho se fala. $\mathrm{O}$ estanho puro, do qual podem ser citados inúmeros testemunhos desde os tempos mais antigos, é inócuo à saúde. Em seguida, é preciso considerar o estanho tal como é comumente usado. Especificamente, o arsênio, que eles demonstraram existir nos estanhos ingleses tão usados na França, constituía de fato uma ameaça séria à saúde? O estanho inglês continha, conforme eles próprios haviam estabelecido, uma proporção máxima de 1/576, mas freqüentemente se encontrava uma razão de 1/1152 de arsênio ou de 1/768. Eles decidiram inicialmente tomar então um valor médio de 1/832, observando, contudo, que na prática o teor era ainda menor em decorrência do hábito de misturar o estanho puro das Índias com o inglês. No entanto, para ter uma maior margem de segurança, decidiram usar o teor mais alto, ou seja, 1/576. Em segundo lugar, ressaltaram que o arsênio no estanho nunca está na forma de cal, isto é, de arsênico $\left(\mathrm{As}_{2} \mathrm{O}_{3}\right)$, mas sim na forma de régulo (arsênio elementar). Era um fato bem conhecido dos químicos que o régulo, embora tóxico, era bem menos temível que sua cal. Eles decidiram fazer experiências com animais, para as quais poderiam ser adotados dois procedimentos diferentes: o primeiro consistiria em administrar-lhes estanho com um teor de 1/576 de arsênio e, a parrtir daí, ir aumentando gradativamente o teor do contaminante para estudar os efeitos resultantes; o segundo procedimento seria começar com um estanho com um teor já bem maior de arsênio. Este segundo procedimento foi aquele escolhido. Para este fim prepararam uma liga com a proporção de 1/64 de arsênio. Uma lâmina desta liga foi atacada por duas colheradas de vinagre forte e todo o conjunto usado no cozimento de uma libra de carne. A carne foi dada a um cão vadio trazido das ruas, que a comeu toda no dia 23 de maio de 1778 , sem qualquer efeito nocivo aparente. No dia seguinte, uma alimentação análoga foi dada ao cão, também sem qualquer surpresa. A etapa seguinte consistiu em preparar a carne da maneira anterior, mas com a adição de 16 grãos adicionais da liga sob a forma de limalha fina. Durante mais quatro dias o cão foi assim alimentado de manhã e à tarde, sem qualquer efeito perceptível. Decidiu-se dobrar a dose de limalha, mas antes que isso pudesse ser feito, o cão escapou e voltou à vida das ruas, interrompendo o curso dos experimentos. Para substituí-lo, conseguiram uma cadelinha de raça spaniel, acostumada em seus três anos de vida a só comer carne, miolo de pão e torrões de açúcar. A dieta da cadela foi mantida, mas a carne que lhe era dada passou a ter estanho contendo quantidades crescentes de arsênio. Ao longo de 33 dias a cadela comeu em sua carne um total de 528 grãos de estanho em liga com 15,25 grãos de régulo de arsênio, sendo que nos últimos 3 dias o teor de arsênio já havia atingido a razão de 1/16. Não se observou nenhuma alteração física ou comportamental na cadela.

Os dois pesquisadores decidiram então fazer a experiência com seres humanos, eles próprios. Durante dois anos serviram-se de um prato de estanho comprado em Londres, que continha 3/4 de grão de arsênio por onça. Desse prato, eles comeram tanto cozido como sopa ou qualquer outro alimento. Depois de dois anos de uso, eles nada sentiam e a massa do prato era a mesma, 1 libra, 3 onças e 3,5 gros. A balança que eles usavam acusava facilmente a massa de 4 gros. Supondo então que um prato de estanho pudesse perder algumas partículas de seu material aos alimentos que contivesse, e que cinco pessoas de uma mesma família usassem diariamente aquele prato, podia-se imaginar, com algum exagero, uma perda de 5 gros de seu peso pelo contato ou atrito com os alimentos, ou por outros motivos. Isso significaria que cada membro da família ingeriria no espaço de uma ano um total de 36 grãos de estanho, o que equivale a 3 grãos por mês, ou 1/10 de grão por dia. Este décimo de grão poderia conter 1/5760 de um grão de arsênio. Levando em conta os cálculos feitos, um francês médio gastaria 48 anos para ingerir com os alimentos uma massa de 3 onças de estanho. Como a liga de estanho mais abundante na França tinha um teor de 1/1152 de arsênio, essas 3 onças de estanho conteriam um grão de arsênio. A quantidade é muito pequena e diluída num tempo bastante longo. Aliás, como eles ressaltam, há pelo menos 20 séculos os antepassados dos franceses usam o estanho da Cornualha em seus vasilhames, sem nenhum efeito danoso.

Estavam então respondidas duas questões, a primeira se havia realmente arsênio no estanho, e a segunda, se a presença do arsênio, nas proporções em que se encontrava, era nociva às pessoas.

\section{QUE PERIGO REPRESENTA À SAÚDE A PRESENÇA DE OUTROS METAIS NO ESTANHO?}

Bayen e Charlard propõem-se agora a responder uma terceira e última questão: se os outros metais existentes em liga com o estanho podem tornar seu uso perigoso. Eles começam a discussão repetindo que o estanho puro não pode ser empregado para o fabrico de vasilhame, por ser macio e flexível. Desta maneira, as peças feitas com ele não teriam rigidez e dentro em pouco se tornariam disformes.

O cobre, por exemplo, um dos componentes das ligas de estanho, só é nocivo sob a forma de azinhavre (carbonato básico de cobre). Contudo, ele não sofre esta transformação química quando estiver em liga com o estanho na razão de $1 / 50$ ou mesmo de 1/40. A prata usada em Paris contém 1/24 de cobre, e ninguém tem receio dela. Se então, prossegue o argumento, 23 partes de prata impedem que a parte remanescente de cobre se transforme em azinhavre, com mais razão teores muito maiores de estanho (entre 40 e 50) também impedirão a formação de azinhavre.

No que concerne ao bismuto, eles confessam que suas propriedades toxicológicas ainda eram desconhecidas. Como, porém, ele compartilha de várias propriedades químicas do chumbo pode-se, em princípio. considerá-lo suspeito. No entanto, suas ligas com o estanho têm no máximo o teor de $1 \%$, e suas propriedades individuais se perdem totalmente quando nesta forma.

$\mathrm{O}$ zinco não possui qualquer qualidade nociva à saúde animal. Ademais, seu uso em liga com o estanho é muito restrito, pois se não se tomar muito cuidado, um excesso mínimo de algumas onças dele poderá inutilizar uma batelada de vários quintais de liga, como bem sabem os picheleiros.

$\mathrm{O}$ antimônio, como se disse, ocorre em ligas utilizadas para a 
fabricação de colheres duras e resistentes para os pobres. $\mathrm{O}$ antimônio possui uma característica conhecida há muito tempo: em dose de 6 a 7 grãos ele induz o vômito, e tem sido assim usado em medicina. Em outras palavras, não pode ser considerado um veneno. Todavia, em liga com o estanho em pequenas proporções, a combinação o priva totalmente de suas características eméticas.

Finalmente, resta considerar o chumbo, que Bayen e Charlard denominam "este vil metal". Aqui está para eles o verdadeiro problema de toxidez metálica, sobretudo porque os mestres picheleiros fazem pouco caso das ordenações e abusam do chumbo nas ligas de estanho, já que o primeiro é muito mais barato que o segundo. Para ilustrar, eles dizem que compraram de um mestre picheleiro de estanho uma medida de uma pinta (medida de capacidade que, em Paris, correspondia a 0,93 litro), vendida como sendo de estanho comum de boa qualidade. Eles a encheram de vinagre destilado durante os meses de maio e junho de 1779; após este período, o líquido foi agitado e despejado num frasco de vidro, no fundo do qual se depositou um pó branco que, lavado e secado, pesava entre 14 e 15 grãos: era cal de estanho. O vinagre límpido e incolor teve seu volume reduzido em banho-maria e foi deixado evaporar à secura, obtendo-se 11,5 grãos de sal de saturno (acetato de chumbo). Uma segunda experiência, desta vez com o ácido nítrico, mostrou que aquele estanho tinha um teor de chumbo de $20 \%$. Eles observam, com razão, como seria perigoso guardar vinho ou qualquer outro líquido ácido em vasilhas semelhantes que, infelizmente, são muito comuns. Ao comentarem com um mestre picheleiro sua estupefação a respeito do ocorrido, este lhes disse que havia outros estanhos com mais chumbo ainda, até um teor de $25 \%$. Os autores ressaltam que a prática não só punha em risco a vida das pessoas, como era um roubo, pois vendia-se chumbo por estanho. Como eles dizem, "era nosso dever dar ciência disso, mas é aos magistrados que, sob a autoridade do rei, velam pela segurança dos cidadãos, que está reservado destruir um tal abuso, trazendo os picheleiros de estanho de volta à execução das ordenações" ${ }^{29}$.

\section{CONCLUSÃO}

Após mais algumas considerações a obra termina. Bayen e Charlard souberam executar com maestria a incumbência que lhes havia sido proposta, ampliando a questão inicial e levando a cabo um verdadeiro projeto de pesquisa em torno da química do estanho. Apesar do estado ainda relativamente pouco desenvolvido da química de seu tempo, eles souberam explorar todos os recursos disponíveis e todo o conhecimento existente para se desincumbir da missão. Aliaram a esse conhecimento um aguçado espírito crítico e uma capacidade de raciocínio químico que às vezes surpreende por sua atualidade. O projeto todo levou mais de dois anos para ser ultimado e permanece até hoje como uma pesquisa válida em suas linhas genéricas. É bom lembrar que tudo isso ocorreu antes da finalização da revolução lavoisiana. Basta citar que o marco fundamental desta, a publicação do Tratado Elementar de Química de Lavoisier, só ocorreria oito anos depois do livro de Bayen e Charlard.

\section{REFERÊNCIAS}

1. Bayen, P.; Charlard, L. M.; Recherches Chimiques sur l'Étain, Faites et Publiées par Ordre du Gouvernement, ou Réponse à Cette Question: Peuton sans Aucun Danger Employer les Vaisseaux d'Étain dans l'Usage Économique?, Imprimerie de Philippe-Denys Pierres, Paris, 1781, p. vii.

2. Partington, J. T.; A History of Chemistry, vol. 3, reprint ed., Martino Publishing: New York, 2000, pp. 394-399.

3. Lemery, N.; Cours de Chymie, L.-Ch. D'Houry, Fils, Paris, 1757, pp. 7576.

4. Aqui se vê a influência da doutrina da Tria Prima, ou dos três princípios que compõem os corpos, o enxofre, o mercúrio e o sal. Esses princípios correspondem às qualidades de ser, em diferentes graus, inflamável, fusível e terroso, respectivamente, e não às substâncias que designamos modernamente por esses nomes.

5. Histoire de l'Académie Royale des Sciences. Année 1738, Sur l'Étain, Paris, 1740, pp. 49-51.

6. Geoffroy, C.-J.; Mémoires de l'Académie Royale des Sciences. Année 1738, De l'Étain. Premier Mémoire, Paris, 1740, pp. 103-127.

7. Encyclopaedia Britannica, Micropedia, vol. VIII, Chicago, 1979, p. 985.

8. Ref. 1, p. 14

9. Ref. 1, p. 12-14.

10. J. H. Schulze; Dissertatio Medica, in qua metallicum contagium in ciborum, potium et medicamentorum praeparatione ac asservatione cavendum indicatur: seu Mors in olla, Altdorf, 1722. O título da dissertação pode ser traduzido como: Dissertação médica, na qual é indicado o contágio metálico e o que deve ser evitado na preparação e na conservação dos alimentos, bebidas e medicamentos: ou Morte na panela.

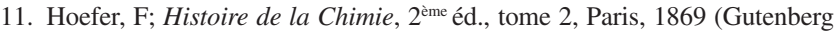
Reprints, 1980), pp. 407-421.

12. Filgueiras, C. A. L.; Quim. Nova 1998, 21, 176.

13. Ref. 1, pp. 9-12, 15-16.

14. As unidades usuais de comprimento na França de então eram o pé, que valia $325 \mathrm{~mm}$, a polegada, equivalente a 1/12 do pé, ou 27,1 mm, e a linha, igual a 1/12 da polegada, ou aproximadamente $2,26 \mathrm{~mm}$. Com relação às unidades de massa, uma libra de $489 \mathrm{~g}$ valia 16 onças, cada onça ( 1 onça $=30,56 \mathrm{~g})$ equivalendo a 8 gros $(1$ gros $=3,8 \mathrm{~g})$, e este, por sua vez, a 72 grãos(1 grão $=0,05 \mathrm{~g})$.

15. Ref. 1, p. 35.

16. Ref. 1, pp. 36-37.

17. Partington, J. T.; A History of Chemistry, vol. 4, reprint ed., Martino Publishing, N. York, 2000, pp. 283-284.

18. 1 dracma corresponde a 60 grãos ou 2,5 escrópulos.

19. Ref. 1, p. 50.

20. Ref. 1, p. 51

21. Ref. 1, p. 53

22. Ref. 1, p. 67. Consideravam-se semi-metais, no século 18, algumas substâncias com propriedades semelhantes aos metais, que eram, porém, sublimáveis ou com baixa ou nenhuma dutilidade. As listas variavam conforme os químicos, e os critérios não eram rígidos. Em geral incluíam o antimônio, o arsênio, o bismuto, assim como o mercúrio. Também podiam conter o cobalto e o zinco, e, mais tarde, também o níquel.

23. Ref. 1, pp. 80-82.

24. Harrison, P. G., ed.; Chemistry of Tin, Blackie, Glasgow, 1989, p. 8.

25. Greenwood, N. N., Earnshaw, A.; Chemistry of the Elements, Pergamon: Oxford, 1984, p. 447.

26. Ref. 1, pp. 132-133.

27. Ref. 1, pp. 152-153.

28. Ref. 1, p. 168 .

29. Ref. 1, p. 258 